\title{
COMPETIÇÃO TRIBUTÁRIA OU GUERRA FISCAL? DO PLANO INTERNACIONAL À LEI COMPLEMENTAR N ${ }^{\circ}$
} $160 / 2017$

\author{
DANIEL VIEIRA MARINS ${ }^{\dagger}$ \\ Gustavo da Gama Vital de OliveIRA ${ }^{\dagger \dagger}$
}

RESUMO: De início, os autores diferenciam o capital de investimento do capital financeiro, em especial quanto à existência de atividade empresarial real ou de mera mobilidade do capital. A seguir, são analisados os conceitos de "paraíso fiscal" e de regime fiscal privilegiado e as regras criadas no plano internacional com o objetivo de regular a competição tributária. Neste aspecto, são destacados os tratados e os acordos multilaterais ("hard law"), as diretrizes da OCDE, as quais são caracterizadas como "soft law", e o entendimento da doutrina quanto ao tema. Os autores também analisam a competição tributária sob a ótica da Lei Complementar $n^{\circ} 24 / 75$ e das novas regras criadas pela Lei Complementar $n^{\circ} 160 / 2017$, tais como a alteração parcial (e insuficiente) da unanimidade nos convênios do ICMS, a aplicação de sanções mais severas ao Estado que descumpre a Lei Complementar $n^{\circ} 24 / 75$ e a atuação do Ministro de Estado da Fazenda nas situações de conflito quanto à concessão de benefícios ou incentivos fiscais. Somando-se a isso, são analisados o posicionamento do Supremo Tribunal Federal quanto à competição tributária prejudicial e o fenômeno da "inconstitucionalidade útil". Ademais, é realizada uma comparação entre as inovações da Lei Complementar $n^{\circ}$ 160/2017 e as regras existentes no direito tributário internacional para regular a competição tributária.

PAlaVRAS-CHAVE: Federalismo fiscal; Competição tributária; OCDE; Paraísos fiscais; Incentivos fiscais.

\footnotetext{
+ Mestre e Doutorando em Direito (Finanças Públicas, Tributação \& Desenvolvimento) pela Universidade do Estado do Rio de Janeiro (UERJ). Procurador da Fazenda Nacional.

++ Professor Adjunto de Direito Financeiro da Universidade do Estado do Rio de Janeiro (UERJ). Doutor e Mestre em Direito Público pela Universidade do Estado do Rio de Janeiro (UERJ). Procurador do Município do Rio de Janeiro. Advogado.
} 
ABSTRACT: Initially, the authors differentiate investment capital from financial capital, especially as regards the existence of real business activity or the mere mobility of capital. Next, the concepts of "tax haven" and privileged tax regime and the rules created at the international level with the purpose of regulating tax competition are analyzed. In this regard, the treaties and multilateral agreements ("hard law"), the OECD guidelines, which are characterized as "soft law", and the understanding of the doctrine on the subject are highlighted. The authors also analyze tax competition from the perspective of Complementary Law No. 24/75 and the new rules created by Complementary Law No. 160/2017, such as the partial (and insufficient) amendment of unanimity in ICMS agreements, the application of more severe sanctions against the State that fails to comply with Complementary Law No. 24/75 and the performance of the Minister of State of Finance in situations of conflict regarding the granting of tax benefits or incentives. In addition, the position of the Federal Supreme Court regarding harmful tax competition and the phenomenon of "useful unconstitutionality" are analyzed. In addition, a comparison is made between the innovations of Complementary Law $n{ }^{\circ} 160 / 2017$ and the existing rules in international tax law to regulate tax competition.

KEYWORDS: Fiscal federalism; Tax competition; OECD; Tax havens; Tax incentives. 


\section{INTRODUÇÃO}

O fenômeno da competição tributária - rotulado, no Brasil, como "guerra fiscal" - não é exclusivo do nosso país. Federações como os Estados Unidos ${ }^{1}$, o Canadá ${ }^{2}$ a Rússia ${ }^{3}$, a Suíç̧a ${ }^{4}$, bem como a própria União Europeia ${ }^{5}$, também têm que lidar com a disputa entre estados no âmbito tributário. Da competição entre estados ou províncias surge a necessidade de se criar regras ou acordos entre os governos subnacionais, de modo a não se desestabilizar as relações dentro da federação.

Mas não só no plano interno ocorre a competição tributária. Na esfera internacional, diversos países se utilizam de benefícios ou incentivos fiscais, da redução da base de cálculo ou da alíquota de tributos, dentre outros instrumentos, para atrair investimentos, seja como capital de investimento (e.g., criação de novas empresas), seja como capital financeiro. Assim, a disputa por espaço na economia globalizada acaba afetando, mesmo que por via reflexa, todos os países, pois a mobilidade do capital faz com que os governos tenham que, permanentemente, se preocupar com as vantagens tributárias criadas por outras nações, sob pena de perderem, ou deixar de receber, capitais de investimento ou financeiros.

Mas se nas federações e nos países descentralizados administrativamente existe a União, ou o governo central, para editar leis ou firmar acordos entre os estados-membros ou províncias para se fixar limites à competição tributária, o que poderia ser feito no plano internacional para se mitigar prejuízos ou evitar abusos por parte dos

\footnotetext{
${ }^{1}$ FOX, William F. The practice of fiscal federalism: comparative perspectives. Org. Anwar Shah. Montreal \& Kingston: McGill-Queen's University Press, 2007, p. 359-360 e 383.

2 BOADWAY, Robin. Canada. In: SHAH, Anwar (Ed.). The practice of fiscal federalism: Comparative perspectives. McGill-Queen's Press-MQUP, 2007, p. 113 e 383.

${ }^{3}$ DERYUGIN, Alexander; KURLYANDSKAYA, Galina. The Russian Federation. In: SHAH, Anwar (Ed.). The practice of fiscal federalism: Comparative perspectives. McGill-Queen's Press-MQUP, 2007, p. 247-250.

${ }^{4}$ KIRCHGÄSSNER, Gebhard. Swiss Confederation. SHAH, Anwar (Ed.). The practice of fiscal federalism: Comparative perspectives. McGill-Queen's Press-MQUP, 2007, p. 329-333 e 383.

${ }^{5}$ LAMPREAVE, Patricia. Fiscal Competitiveness versus Harmful Tax Competition in the European Union. Bulletin for International Taxation, v. 65, p. 1-18.
} 
países? Como e quais seriam as regras capazes de se evitar uma competição tributária prejudicial ou nociva entre os países? E qual seria a fonte dessas regras?

A partir das respostas às perguntas acima, chega-se a um segundo momento de reflexão: poderiam as normas utilizadas no plano internacional para se limitar a competição tributária entre países servir de parâmetro para o enfrentamento da questão na realidade interna brasileira? Quais as diferenças e semelhanças entre as normas internacionais em debate e as regras criadas pela Lei Complementar $n^{\circ}$ 160/2017, que busca regular a competição tributária entre estadosmembros no que tange ao ICMS?

Para tanto, o presente artigo se divide em três partes: a primeira relativa à competição tributária internacional, indicando as espécies de normas e de mecanismos existentes para se combater uma competição demasiadamente prejudicial às economias dos países e nociva ao comércio internacional; a segunda concernente às regras criadas no Brasil por meio da Lei Complementar $n^{\circ}$ 160/2017, estabelecendo as similitudes e as distinções entre as normas existentes na esfera internacional e a recente criação legislativa nacional; e a terceira referente à conclusão do trabalho, em que se sintetizam as reflexões desenvolvidas por todo o artigo, criando um diálogo entre as inovações da Lei Complementar $n^{\circ}$ 160/2017, as normas de Direito Internacional referentes à competição tributária entre países e o futuro da legislação brasileira para fixar regras e limites à disputa fiscal entre os estados-membros.

\section{A COMPETIÇÃO TRIBUTÁRIA INTERNACIONAL}

Com o fim da Segunda Guerra Mundial, diversas colônias europeias localizadas na África e na Ásia iniciaram processos de independência, os quais provocaram a criação de novos países. Nações importantes como a India (1947), o Paquistão (1947), a Indonésia (1945), a Malásia (1957) e a Argélia (1962) somente alcançaram verdadeira autonomia e poder de autodeterminação em razão da reorganização mundial decorrente dos conflitos ocorridos entre 1939 e 1945.

Como consequência do surgimento de novos países, houve a ampliação do campo de atuação do capitalismo mundial. Com mais países, maiores eram as ofertas de governos em favor de empresas, haja vista a necessidade de se criar mercados consumidores internos e se buscar (no caso dos países subdesenvolvidos ou em desenvolvimento) melhores condições para a exportação de produtos para os países centrais (e.g., Estados Unidos, Inglaterra, França etc.). 
A busca dos países periféricos por espaços na economia mundial se manteve altamente limitada até o fim do bloco soviético, com a derrocada do socialismo real. A partir de então, sem os efeitos da Guerra Fria e da existência de economias planificadas e com a perda de força dos Estados do Bem-estar Social, praticamente todos os países se viram dentro do campo de influência do capitalismo global. E a ampla abertura das economias, somada à fluidez e à mobilidade do capital, fez com que uma nova realidade fosse imposta: a inerente competição entre países.

Diversos fatores influenciam o investidor em sua decisão de aplicar ou não recursos em determinado país. No que tange ao capital de investimento (aqui entendido como o capital a ser vinculado à criação ou à aquisição de empresas que desenvolvam atividade de comércio, indústria ou prestação de serviços), a decisão envolve, por exemplo, questões como (i) a existência e a relevância de mercado consumidor interno; (ii) a viabilidade de se exportar e importar produtos; (iii) a segurança jurídica conferida pelo ordenamento jurídico nacional; (iv) a legislação do trabalho; (v) a legislação ambiental; (vi) a perspectiva econômica do país; (vii) a proximidade geográfica do país que receberá o investimento com os países centrais; (viii) os laços diplomáticos entre o país escolhido e o país de origem do investidor; e (ix) a infraestrutura urbana e de logística. Por outro lado, no que concerne ao capital financeiro (aqui considerado o capital especulativo cuja finalidade principal é a maximização dos lucros), fatores como (i) a segurança jurídica, (ii) a flexibilidade da legislação financeira e (iii) a proteção ao sigilo de dados terão mais importância na tomada de decisão pelo detentor do capital. ${ }^{6}$

"Como se verá a seguir, a divisão do capital em "financeiro" e "de investimento" é fundamental para se analisar corretamente a competição tributária internacional. Isto porque os objetivos buscados por cada uma dessas espécies de capital são diferentes, seja no que se refere à forma de aplicação, seja no que diz respeito à obtenção do lucro. Em sentido semelhante: RIXEN, Thomas. Tax Competition and Inequality - The Case for Global Tax Governance. Global Governance: A Review of Multilateralism and International Institutions, Vol. 17, 2011, p. 05-07. Nota-se que Thomas Rixen divide a competição tributária internacional em duas modalidades: a competição por investimentos estrangeiros diretos ("foreign direct investment") e a competição pelos chamados "lucros de papel" ("mobile 'paper' profits"). Enquanto na primeira a carga tributária real teria um fator importante, porém limitado a outros fatores que também influenciam o investimento (e.g., educação, custo do trabalho, qualidade da infraestrutura), na segunda o fator decisivo seria a "taxa de tributação nominal" ("nominal tax rate"), pois apenas os lucros que não podem ser compensados contra a depreciação através de outros benefícios fiscais, precisam ser transferidos para obter 
De qualquer forma, seja no caso do capital de investimento, seja na hipótese do capital financeiro, um dos principais fatores levados em conta no processo de tomada decisão na aplicação do capital é a tributação. A depender da carga tributária, o retorno econômico poderá ser considerado alto, mediano em comparação a outras nações ou mesmo inexistente, o que impedirá a realização do negócio.

É justamente diante dessa realidade que os países disputam espaço na economia global: há um complexo de fatores que, ao serem conjugados, fará com que um investimento seja realizado em determinado país, e não em outro; ou que uma movimentação financeira seja efetuada em direção a certo país e não a outro. Na busca por capital, cada país deve aplicar as políticas públicas que melhor atendam aos seus interesses, sob pena de perderam espaço para os demais. ${ }^{7}$

Assim, a competição tributária surge como um dos instrumentos capazes de auxiliar os governos (ou seus governantes, a depender do nível de consolidação da democracia)na atração de capital, independentemente da sua natureza.

Quanto ao capital de investimento, as políticas fiscais mais adotadas dizem respeito à concessão de benefícios ou incentivos fiscais atinentes à tributação sobre o consumo. Isto porque, em regra, o capital de investimento provoca ou (i) a mudança de um investimento já existente em um país para outro ou (ii) a aplicação de um novo investimento em determinado governo nacional em detrimento dos demais. No primeiro caso, há o efetivo descolamento do capital, o que provoca a perda de um investimento anterior para a criação de um novo (e.g., transferência de

economias reais (RIXEN, Thomas. Tax Competition and Inequality - The Case for Global Tax Governance. Global Governance: A Review of Multilateralism and International Institutions, Vol. 17, 2011, p. 6).

${ }_{7}$ Segundo Andre Moriss e Lotta Moberg, "[...] States compete for economic activity in multiple ways, including offering different mixes of security of ownership, access to resources, regulatory climates, and demands on investors to share resources. Tax competition is but one aspect of this competition. [...]". E, ao concluírem a análise inicial sobre a competição entre jurisdições, acrescentam: " [...] tax policy is just one of many dimensions on which nations compete for economic activities. An educated workforce, widespread use of languages common in international trade, the size of a particular market, a common law legal system, being in the "right" time zone, and the presence of a "creative class" are all regularly linked to economic success. Taxation is no different in principle from these other characteristics. [...]"(MORRISS, Andrew P.; MOBERG, Lotta, Cartelizing Taxes: Understanding the OECD's Campaign Against 'Harmful Tax Competition'. Columbia Journal of Tax Law, v. 4, n. 1, 2013, p. 05 e 14). 
plantas industriais, fábricas, usinas). Já no segundo caso, existe uma espécie de concurso entre países a fim de se influenciar a decisão do investidor. Assim, no caso em tela, ou há a transferência de um capital que já abrange ativos fixos (que fazem parte da economia de outro país) ou há a aplicação de um novo capital (que criará uma nova empresa). Em ambos os casos, o capital transferido não é financeiro ou de caráter especulativo, mas sim com o objetivo de gerar lucro a partir de ativos a serem vinculados a uma atividade econômica privada.

Ademais, por mais que a facilitação na utilização de prejuízos fiscais e de deduções na tributação sobre a renda faça com que o investidor se sinta estimulado a adquirir empresas no país, será a concessão de benefícios ou incentivos fiscais de impostos incidentes sobre o consumo que criará o ambiente mais vantajoso economicamente para as empresas que desenvolvem atividades de comércio, indústria ou de prestação de serviços. O foco do capital de investimento, sob esta ótica, é a maior obtenção de lucro a partir da compra e venda de produtos e da prestação de serviços, uma vez que a redução do preço final do bem é o objetivo principal do investidor da chamada "atividade empresarial real". ${ }^{8}$

Em contrapartida, ao se tratar do capital financeiro, a questão tributária principal é a drástica diminuição da tributação sobre a renda e o patrimônio. Para o capital de natureza especulativa, a tributação sobre o consumo não possui qualquer relevância, pois a obtenção de lucro não decorre da compra e venda de produtos ou da prestação de serviços, mas, sim, da própria aplicação financeira(e do posterior resgate) por meio da mobilidade do capital. Na realidade, o capital financeiro é deslocado unicamente para se obter uma maximização dos lucros, o que, em regra, resulta em transferências artificiais, tais como destacado por Thomas Rixen no caso dos "paper profits". ${ }^{9}$

Logo, para o capital financeiro, o que importa é a forma da distribuição de lucros ou dividendos ou da aquisição da disponibilidade econômica e jurídica sobre a renda. Vale dizer, o que é relevante é a baixa (ou mesmo inexistente) tributação sobre a renda e o patrimônio, pois isto que maximizará os lucros do detentor do capital.

\footnotetext{
${ }^{8}$ A expressão ("real business activity") é utilizada por Thomas Rixen justamente para distinguir o "foreign direct investment" (FDI) das atividades financeiras que tão somente transferem o lucro de um país para outro (RIXEN, Thomas. Tax Competition and Inequality - The Case for Global Tax Governance. Global Governance: A Review of Multilateralism and International Institutions, v. 17, 2011, p. 05-06).

9 RIXEN, Thomas. Tax Competition and Inequality - The Case for Global Tax Governance. Global Governance: A Review of Multilateralism and International Institutions, v. 17, 2011, p. 06-07).
} 
A distinção das duas realidades (capital de investimento versus capital financeiro) é essencial para que não se cometa o erro de se analisar a competição tributária internacional sob um prisma único de aplicação de políticas públicas. Igualar o capital de investimento ao capital financeiro significa ignorar diferenças relevantes quanto às suas estruturas e características fundamentais, o que gera uma conclusão equivocada no momento de se lidar com o problema da competição tributária prejudicial. ${ }^{10}$

No plano internacional, o foco principal de insatisfação por parte de certos países é a competição tributária envolvendo o capital financeiro. Isto porque diversos países têm reduzido drasticamente a tributação sobre o patrimônio e a renda, incentivando a alteração de domicílio de pessoas físicas e jurídicas e a criação de empresas subsidiárias com o único fim de se pagar menos imposto de renda. São os chamados "paraísos fiscais" ("tax havens"), conceituados como países com tributação favorecida ou de regimes fiscais privilegiados pela legislação brasileira. ${ }^{11}$

No plano doutrinário, a conceituação e a caracterização dos "paraísos fiscais" não são uniformes. Para Thomas Rixen, os "tax havens" seriam países com baixa atividade econômica real, cuja economia dependeria fundamentalmente da sua operação como "tax shelters" (leia-se, como países para se evitar ou diminuir drasticamente o pagamento de tributos), fruto da comercialização da sua soberania fiscal. Segundo Rixen, os "paraísos fiscais" oferecem carga tributária zero ou muito baixa, sigilo fiscal ou leis que permitem que os contribuintes estrangeiros criem "empresas de fachada" ("shell companies"). ${ }^{12}$ Por outro lado, Andrew Moriss e Lotta Moberg distinguem os "paraísos fiscais" dos chamados países com regime fiscal privilegiado, uma vez que os últimos possuem um sistema de separação, proteção e sigilo de ativos financeiros,

\footnotetext{
${ }^{10}$ Percebe-se que até mesmo autores que reconhecem expressamente a distinção entre a competição pelo capital de investimento da competição pelo capital financeiro acabam apresentando argumentos conflitantes sobre o tema. Neste sentido, veja-se Thomas Rixen ao tratar dos efeitos nocivos da competição tributária entre países, em especial no que tange às nações africanas (RIXEN, Thomas. Tax Competition and Inequality The Case for Global Tax Governance. Global Governance: A Review of Multilateralism and International Institutions, v. 17, 2011, p. 09-12).

${ }^{11}$ Vide art. $2^{\circ}$ da IN SRF 407/2004, art. $1^{\circ}$ da IN RFB 1037/2010 e art. 24 da Lei $n^{\circ}$ 9.430/96.

12 RIXEN, Thomas. Tax Competition and Inequality - The Case for Global Tax Governance. Global Governance: A Review of Multilateralism and International Institutions, v. 17, 2011, p. 11.
} 
enquanto os primeiros se caracterizam por não ter uma atividade econômica substantiva. ${ }^{13}$

No ordenamento jurídico pátrio, são considerados países com tributação favorecida aqueles que não tributem a renda ou a tributem com a alíquota máxima inferior a $20 \%$ (art. 24, caput, da Lei $\mathrm{n}^{\circ} 9.430 / 96$ ) ou cuja legislação não permita o acesso a informações concernentes à composição do quadro de sócios da pessoa jurídica, à titularidade da empresa ou à identificação do real beneficiário dos rendimentos atribuídos a não residentes (art. 24, $4^{\circ}$, da Lei $\mathrm{n}^{\circ}$ 9.430/96). Paralelamente, a legislação considera como regime fiscal privilegiado aquele que (i) ou não tribute a renda ou a tribute à alíquota máxima inferior a $20 \%$, (ii) ou conceda vantagem de natureza fiscal a pessoa física ou jurídica não residente sem exigência de realização de atividade econômica substantiva no país, ou dependência, e condicionada ao não exercício de atividade econômica substantiva no país ou dependência; (iii) não tribute, ou o faça em alíquota máxima inferior a $20 \%$ (vinte por cento), os rendimentos auferidos fora de seu território; (iv) ou não permita o acesso a informações relativas à composição societária, titularidade de bens ou direitos ou às operações econômicas realizadas (art. 24-A, parágrafo único, da Lei $\mathrm{n}^{\circ} 9.430 / 96$, incluído pela Lei $\mathrm{n}^{\circ}$ $11.727 / 2008)$.

A fim de tornar claro que nações o governo federal considera países com tributação favorecida ou de regimes fiscais privilegiados, foi publicada a IN RFB 1037/2010, cujo art. $1^{\underline{0}}$ traz uma extensa lista de países que não tributam a renda ou que a tributam à alíquota inferior a $20 \%$ (vinte por cento). Além disso, o art. $2^{\circ}$ da Instrução Normativa indica quais são os regimes fiscais privilegiados, descrevendo até que espécies de pessoas jurídicas terão tratamento diferenciado pela Receita Federal do Brasil. ${ }^{14}$

Contudo, a existência de legislação interna indicando que países são considerados "paraísos fiscais" e determinando que a administração

${ }^{13}$ MORRISS, Andrew P.; MOBERG, Lotta, Cartelizing Taxes: Understanding the OECD's Campaign Against 'Harmful Tax Competition'. Columbia Journal of Tax Law, v. 4, n. 1, 2013, p. 43.

${ }^{14} \mathrm{~A}$ lista de mais de cinquenta países foi atualizada pela IN RFB 1658/2016. Os principais destaques dizem respeito à inclusão da Irlanda na lista de países com tributação favorecida e a manutenção das pessoas jurídicas constituídas sob a forma de Limited Liability Company ( $L L C$ ) estaduais, cuja participação seja composta de não residentes, não sujeitas ao imposto de renda federal, situadas nos Estados Unidos da América como sendo de regime fiscal privilegiado. Por outro lado, as Antilhas Holandesas e a Suíça foram retiradas da lista. 
tributária nacional trate estes países de forma distinta dos demais não é suficiente para se enfrentar a competição tributária internacional. Isto porque, sob o prisma do Direito Internacional, a legislação interna, por si mesma, não possui validade e eficácia extraterritorial - até porque, na visão dos demais ordenamentos jurídicos, a fonte legislativa da competência tributária é a Constituição ou lei fundamental de cada país.

Assim, uma vez que não existe uma organização tributária internacional ou qualquer estrutura hierárquica supranacional que abarque todas as nações no âmbito fiscal ${ }^{15}$, como poderiam os países que se sentem prejudicados por determinadas formas de competição tributária compelir os demais a alterar sua legislação tributária? Em outras palavras, no plano do Direito Tributário Internacional, haveria como se obrigar os "paraísos fiscais" a acabar com a ínfima, ou quase nula, tributação sobre a renda e o patrimônio daqueles que, como a nítida intenção de tão somente não pagar tributos, criam empresas e geram domicílios fiscais artificiais, promovendo a erosão das bases tributárias?

A solução para o problema não é simples e ainda gera reflexões e questionamentos tanto no campo doutrinário quanto na esfera intergovernamental. Se no campo do comércio internacional e dos direitos trabalhistas existem a Organização Mundial do Comércio (OMC) e a Organização Internacional do Trabalho (OIT) que podem estabelecer novas regras e criar mecanismos de sanção, no âmbito fiscal, nota-se que, em algumas ocasiões, certos países exercem a sua competência tributária sem maiores preocupações quanto aos possíveis prejuízos causados em outras nações.

Ao cuidar da aplicação do "hard law," "customary law" e "soft law" na tributação internacional, Allison Christians se debruça sobre o grau de vinculação ou obrigação que os países têm em relação às normas internacionais na esfera tributária. ${ }^{16}$ No que tange ao "hard law" (e.g., tratados), a matéria não gera maiores debates, pois, em havendo a manifestação de vontade do próprio país, há um consenso fixado formalmente que vincula as partes (e.g., acordos multilaterais). No

\footnotetext{
${ }^{15}$ Alguns estudiosos defendem a existência de uma organização tributária internacional com poderes de sanção sobre os países que desrespeitassem as normas de combate à competição tributária (RIXEN, Thomas. Tax Competition and Inequality - The Case for Global Tax Governance. Global Governance: A Review of Multilateralism and International Institutions, v. 17, 2011, p. 20 e 23-24). Contudo a ideia se mantem muito distante da realidade atual, em razão da enorme dificuldade política na sua criação.

${ }_{16}$ CHRISTIANS, Allison. Hard Law \& Soft Law in International Taxation. Wisconsin International Law Journal, v. 25, n. 2, 2007, p. 02-03.
} 
entanto, ao analisar o "customary law" e o "soft law", nota-se que o caráter vinculante muda de figura, tendo-se, em primeiro lugar, que conceituar ambos os institutos para depois observar como os países têm se comportando diante dessas normas.

O ponto de partida da análise feita por Allison Christians são as regras sobre o tema criadas pela Organização para a Cooperação e Desenvolvimento Econômico (OCDE), as quais surgiram a partir da publicação, em 1998, de um relatório que desenvolveu critérios para identificar a competição tributária prejudicial ("harmful tax competition"). ${ }^{17}$ Com base nessas diretrizes, a OCDE, por meio do diálogo, da busca pelo consenso e da"peer pressure" ${ }^{\prime 18}$, desenvolveu normas de tributação internacional objetivando redefinir as práticas fiscais internacionais. Curiosamente, tais normas de combate às práticas consideradas prejudiciais ou nocivas à tributação internacional se expandiram e se disseminaram por diversos países que não fazem parte da $\mathrm{OCDE},{ }^{19}$ o que gerou reflexões sobre a natureza dessas recomendações e diretrizes. Isto é, as normas da OCDE visando ao combate à competição tributária prejudicial ("harmful tax competition") seriam espécie de Direito Internacional? Seriam forma de direito consuetudinário ("customary law") ou de "soft law"?20

${ }_{17} \mathrm{O}$ relatório foi consolidado na publicação Organisation for Economic Co-operation and Development, Harmful Tax Competition: An Emerging Global Issue, 1998.

${ }^{18}$ Segundo a OCDE, "peer pressure" significa a influência e a persuasão exercidas pelos pares durante o processo de negociação. A pressão dos pares não assume a forma de atos juridicamente vinculantes, tais como sanções ou outros mecanismos de execução. Na realidade, seria um meio de persuasão suave que pode se tornar uma força motriz importante para estimular o Estado a mudar, alcançar objetivos e cumprir os padrões e as diretrizes da OCDE (Peer pressure: a related concept. Disponível em:

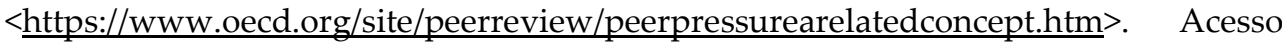
em: 29 set. 2017).

19 Vale lembrar que a OCDE é composta por apenas trinta e cinco países, em sua maioria nações europeias com alto nível de desenvolvimento. Dentre os países em desenvolvimento, fazem parte somente o Chile (desde 1971), a Coréia do Sul (desde 1996), o México (desde 1994) e a Turquia (desde 1961). Logo, vê-se que os membros do chamado "BRICS" (Brasil, Rússia, Índia, China e África do Sul) não participam dos debates, análises e decisões da OCDE, o que limita a legitimidade da organização para estabelecer normas de caráter internacional. A lista com os membros da OCDE está disponível em: $<\underline{\text { http://www.oecd.org/about/membersandpartners/list-oecd-member- }}$ countries.htm>. Acesso em: 22 out.2017.

${ }^{20}$ CHRISTIANS, Allison. Hard Law \& Soft Law in International Taxation. Wisconsin International Law Journal, v. 25, n. 2, 2007, p. 04-05. 
Em linhas gerais, o "customary law" é compreendido como uma espécie de norma internacional que os Estados cumprem de maneira uniforme e que assim o fazem em razão de uma percepção de que há uma obrigação legal nessa forma de agir. Ou seja, para se reconhecer a ocorrência de uma modalidade de direito consuetudinário, deve haver uma regra cujo cumprimento é entendido como obrigatório para a imensa maioria dos países. ${ }^{21}$ Por outro lado, o "soft law" seria uma norma que, apesar de não ser entendida como um direito propriamente dito, gera efeitos que suscitam um processo legal. Vale dizer, não obstante não possuírem as características próprias de direito (tal como as presentes no "hard law" e no "customary law"), o "soft law" promove um senso de obrigação que compele os Estados a agirem de determinada forma. ${ }^{22}$ Daí o porquê de Allison Christians afirmar que

In the customary law realm, a custom could exist in the absence of law-the result is not customary law but simply widespread practice. Using this framework, a binary view suggests that soft law is nothing more than a norm that exists in the absence of law-the outcome again is simply widespread practice..$^{23}$

Por conseguinte, Christians não só reconhece que as recomendações e diretrizes da OCDE para o combate da competição tributária prejudicial são espécie de "soft law", como também reforça a importância de se caracterizá-la como tal, pois as normas criadas pela OCDE têm feito com que diversas legislações sobre o tema tenham sido editadas em países que não são membros da organização. ${ }^{24} \mathrm{Em}$ suma, não há como negar que as

${ }^{21}$ CHRISTIANS, Allison. Hard Law \& Soft Law in International Taxation. Wisconsin International Law Journal, v. 25, n. 2, 2007, p. 05-06.

${ }^{22}$ CHRISTIANS, Allison. Hard Law \& Soft Law in International Taxation. Wisconsin International Law Journal, v. 25, n. 2, 2007, p. 07.

${ }^{23}$ CHRISTIANS, Allison. Hard Law \& Soft Law in International Taxation. Wisconsin International Law Journal, v. 25, n. 2, 2007, p. 08.

${ }^{24} \mathrm{Na}$ mesma linha, Andre Moriss e Lotta Moberg afirmam que "[...] the OECD provides important "soft law" that guides international tax law "by issuing commentary, guidelines, best practices, and the like. [...]". Além disso, ambos asseveram que "[...] the OECD is in the process of creating new soft law standards that influence the discussion of tax issues by changing the legal framework within which those issues are discussed. [...]" (MORRISS, Andrew P.; MOBERG, Lotta, Cartelizing Taxes: 
normas tributárias da OCDE têm sido "supranacionalizadas" em algumas áreas, mesmo que o fenômeno não signifique que exista uma globalização do Direito Tributário. ${ }^{25}$

Contudo a admissão de que as recomendações e diretrizes da OCDE possam ser consideradas fontes do direito enfrenta um obstáculo relevante: a ausência de uma organização com um corpo de funcionários indicados pela grande maioria dos países. Não havendo uma estrutura com representantes do governo da maior parte das nações, inclusive eleitos, em formato similar à Organização Mundial do Comércio (em que os acordos são negociados e assinados pelos governos e posteriormente ratificados pelos respectivos parlamentos) $)^{26}$, questiona-se a legitimidade da OCDE para estabelecer recomendações e diretrizes para todas as nações.

Em todo caso, fato é que as diretrizes e as recomendações da OCDE têm se expandido, de modo que a visão tradicional no sentido de que a política fiscal diz respeito unicamente a cada país, em razão da sua autonomia e soberania, independentemente da política fiscal adotada pelos demais países - em especial, aqueles com os quais se desenvolve relações comerciais - merece ser objeto de críticas. ${ }^{27}$

Uma das abordagens mais interessantes sobre o tema tem como cerne a compreensão dos deveres correlacionados à soberania ("sovereign duties"). ${ }^{28}$ Sob esta ótica, cada estado tem o dever de respeitar a competência tributária dos demais, mesmo que isso envolva a

Understanding the OECD's Campaign Against 'Harmful Tax Competition'. Columbia Journal of Tax Law, v. 4, n. 1, 2013, p. 21 e 55).

${ }^{25}$ CHRISTIANS, Allison. Hard Law \& Soft Law in International Taxation. Wisconsin International Law Journal, v. 25, n. 2, 2007, p. 09.

${ }^{26}$ Vide seção "The WTO... ... In brief" da Organização Mundial do Comércio (OMC). Disponível em:

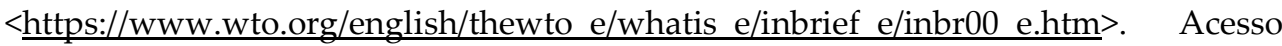
em 29 set. 2017.

${ }^{27}$ Nesse sentido, veja-se, mais uma vez, os comentários de Thomas Rixen: "[...] I have argued that, contrary to claims of an influential part of the literature, national tax policy choices do cause significant externalities on other nation states. Tax competition undermines the integrity and distributive principles of domestic tax structures and aggravates the inequality between developed and developing countries." (RIXEN, Thomas. Tax Competition and Inequality - The Case for Global Tax Governance. Global Governance: A Review of Multilateralism and International Institutions, v. 17, 2011, p. 23).

${ }^{28} \mathrm{O}$ tema é abordado com profundidade por Allison Christians no artigo "Sovereignty, Taxation, and Social Contract", de agosto de 2008. 
bitributação (decorrente da interação entre a "tributação na fonte" e a "tributação no domicílio"). ${ }^{29}$ Neste aspecto, o respeito mútuo entre os países em relação à competência tributária de cada estado é a regra na tributação internacional, o que revelaria o reconhecimento do dever de soberania ("sovereign duty"), isto é, "[...] state shave a duty to respect the sovereign right of other states to tax, even to the extent of not interfering with extra-territorial claims based on currently-accepted jurisdictional connections $[\ldots]^{\prime \prime} .{ }^{30}$

Por sinal, a possibilidade de sobreposição no exercício da competência tributária é tão aceita no âmbito internacional que os próprios países têm procurado diminuir os problemas resultantes da bitributação, seja por meio de tratados bilaterais ou acordos multilaterais, seja de maneira unilateral, a partir da legislação doméstica (e.g., "foreign tax credit"). ${ }^{31}$ Assim, percebe-se que o respeito mútuo não diminui a soberania dos países, mas, ao contrário, a reforça, pois se reconhece a legitimidade de cada nação exercer a sua própria competência tributária - o que envolve a criação de mecanismos que evitem a sobreposição de tributos.

Há, portanto, uma coordenação entre os países ao se exercer a soberania, o que evidencia a existência de "deveres positivos" na relação entre os governos. Isto é, não basta que cada país não interfira nos assuntos internos uns dos outros (e.g., guerras, intervenções militares). É necessário que cada nação pratique atos que reconheçam e respeitem a soberania dos demais, tal como ocorre na esfera tributária internacional com o "hard law", o direito consuetudinário e o "soft law".

Por conseguinte, percebe-se que a competição tributária internacional, no que diz respeito ao capital financeiro, é objeto de regulação tanto no plano interno quanto externo. No âmbito governamental, cada país busca editar leis que conceituem os "paraísos fiscais" e os regimes fiscais privilegiados, de modo que se crie um patamar mínimo na tributação sobre o patrimônio e a renda - tal como feito no Brasil pelas Leis $\mathrm{n}^{\circ}$ $9.430 / 96 \mathrm{e}^{\circ}$ 11.727/2008. Com isso, ao menos no que tange às movimentações financeiras e aos negócios jurídicos realizados diretamente com uma pessoa física ou jurídica sediada no país criador da

${ }^{29}$ CHRISTIANS, Allison. Sovereignty, Taxation, and Social Contract. Minnesota Journal of International Law, v. 18, 2008, p. 09-10.

${ }^{30}$ CHRISTIANS, Allison. Sovereignty, Taxation, and Social Contract. Minnesota Journal of International Law, v. 18, 2008, p. 10.

${ }^{31}$ CHRISTIANS, Allison. Sovereignty, Taxation, and Social Contract. Minnesota Journal of International Law, v. 18, 2008, p. 11-12. 
norma, se impõe um limite à erosão das bases tributárias, mitigando-se os efeitos da competição tributária prejudicial.

Entretanto, em virtude dos efeitos limitados da legislação interna de cada país, se tornou necessária a criação de normas ou diretrizes internacionais, a fim de se enfrentar a amplitude da "harmful tax competition" em um mundo globalizado. Assim, atualmente, na esfera internacional, duas são as formas de se lidar com a competição tributária nociva: ou através de tratados ou acordos multilaterais, nos quais os países manifestam a sua vontade no sentido de eliminar as normas tributárias que viabilizem o surgimento de "paraísos fiscais" e regimes fiscais privilegiados ("hard law"); ou por meio de normas ou diretrizes que, apesar de não serem reconhecidas como direito propriamente dito, geram efeitos que suscitam um processo legal ("soft law"). Dentre ambas, a segunda forma têm se revelado um instrumento mais eficaz para a limitação da competição tributária prejudicial, em especial em razão do sucesso das diretrizes e recomendações fixadas pela OCDE.

\section{O CASO BRASILEIRO: A LC 160/2017}

Na realidade brasileira observada há décadas, a guerra fiscal verificase pela aprovação, pelos Estados, de atos normativos concedendo benefícios fiscais de ICMS, na forma de diminuições de alíquotas, reduções da base de cálculo, isenções, créditos presumidos e outras formas de redução da efetiva carga tributária do imposto.

A Constituição de 1988 (CF) exige, contudo, que os benefícios fiscais de ICMS observem a deliberação dos Estados, segundo a Lei Complementar (art. 155, § 20, XII, “g”). A Lei Complementar $\mathrm{n}^{\circ} 24 / 75$, por sua vez, estabelece que a concessão de benefícios fiscais de ICMS depende sempre de decisão unânime dos Estados representados (art. $2^{\circ}, \S 2^{\circ}$ ), o que macularia com o vício da inconstitucionalidade todos os atos normativos estaduais que concedam benefícios e incentivos fiscais sem obedecer às regras citadas.

A justificativa da regra da unanimidade costuma ser desenvolvida a partir da própria natureza do ICMS, como imposto que afeta a produção e circulação de mercadorias em âmbito nacional, de forma que os benefícios fiscais do tributo teriam efeito potencial de ocasionar reflexos econômicos em outras Unidades Federativas, apesar da competência tributária estadual. Logo, seria essencial que todos os governos subnacionais concordassem com a criação dos benefícios, impedindo-se privilégios ou prejuízos dirigidos aos governos subnacionais. A regra da unanimidade, contudo, causa diversos problemas práticos, pois basta que 
apenas um único governo subnacional não concorde com a proposta de benefício para que seja rejeitada. ${ }^{32}$

O posicionamento histórico do Supremo Tribunal Federal (STF) sempre foi no sentido de reconhecer a inconstitucionalidade de centenas de leis estaduais que não observaram a regra da unanimidade das deliberações do Conselho Nacional de Política Fazendária (CONFAZ), buscando assim conferir efetividade à LC 24/75.

Logo, considerando as manifestações explicitadas na parte inicial de nosso trabalho, podemos afirmar que as regras sobre competição fiscal no Brasil, em relação aos Estados, adotam claramente o critério da "hard law", visto que são formadas por normas consagradas em lei e cujo descumprimento sujeitam o Estado infrator a procedimento judicial no STF, que funciona como o guardião do referido sistema. O problema brasileiro é a baixa eficácia do sistema de "hard law" interno, conforme veremos.

Isto porque a firme atuação do STF mostrou-se ineficaz, pois os Estados continuavam editando novas leis de benefícios fiscais de ICMS, bastante semelhantes, em muitos casos, às declaradas inconstitucionais. Ainda há a prática reiterada de revogar a lei estadual de benefício fiscal às vésperas do julgamento da ADI em face da norma, para tornar necessária a perda de objeto da ADI e evitar o julgamento da inconstitucionalidade pelo STF. ${ }^{33}$

Tais circunstâncias garantiam assim para os Estados a certeza de que suas leis estaduais, ainda que fossem declaradas inconstitucionais, teriam sua eficácia assegurada por tempo bastante razoável, de forma a atender a demanda dos setores empresariais interessados nos investimentos, gerando o fenômeno conhecido como "inconstitucionalidade útil".

A insegurança jurídica do contribuinte beneficiário de incentivo fiscal tornou-se ainda mais grave porque o Estado de destino das mercadorias considera, por decisão própria, inconstitucional o benefício fiscal conferido pelo Estado de origem (mesmo sem o julgamento de uma ação direta de inconstitucionalidade pelo STF) e desconsidera assim o crédito apresentado pelo contribuinte (glosa), exigindo o tributo de forma integral no destino, como se nenhum valor tivesse sido recolhido na origem. Isto porque a Lei Complementar $n^{\circ} 24 / 75$ consagra no art. $8^{\circ}$ a

${ }^{32}$ Vale ressaltar que há Arguição de Descumprimento de Preceito Fundamental 198 (Rel. Ministro Dias Toffoli), pendente de julgamento, questionando a recepção da regra de unanimidade para a concessão de benefícios fiscais do ICMS pela Constituição de 1988.

33 VARGA, Caio Amuri. Guerra fiscal - ausência de coordenação na política pública tributária nacional. Revista Tributária e de Finanças Públicas, v. 122, 2015, p. 245-263. 
expressa ineficácia do crédito fiscal atribuído ao estabelecimento recebedor da mercadoria, bem como a exigibilidade do imposto não pago ou devolvido.

Todavia, tal procedimento de autotutela, sem a prévia declaração pelo STF da inconstitucionalidade da lei estadual, enfrenta severas críticas da doutrina ${ }^{34}$ que costuma advogar que o art. $8^{\circ}$ da LC 24/75 não foi recepcionado pela $\mathrm{CF}^{35}$ Ademais, o procedimento não é aceito pela jurisprudência do Superior Tribunal de Justiça ${ }^{36}$, havendo ainda repercussão geral com julgamento de mérito pendente de análise no Supremo Tribunal Federal (RE 628075, rel. Ministro Joaquim Barbosa, julgado em 13.10.2011).

Vale ressaltar ainda que, em algumas oportunidades mais recentes, o STF reconheceu a eficácia ex nunc da declaração de inconstitucionalidade de lei de benefício fiscal em desacordo com a Lei Complementar $n^{\circ} 24 / 75$, ou seja, admitindo como válidos os efeitos produzidos pela lei declarada inconstitucional até a data do julgamento. ${ }^{37}$

De forma a combater a limitada eficácia do controle abstrato de inconstitucionalidade das leis estaduais inconstitucionais, houve ampla discussão pelo STF e na classe política acerca da possibilidade de se criar uma Súmula Vinculante sobre a matéria, cujo conteúdo, em linhas gerais, afirmaria que qualquer benefício fiscal relativo ao ICMS, concedido sem prévia aprovação em convênio celebrado no âmbito do CONFAZ, seria inconstitucional. Para os defensores da tese, haveria significativo ganho de celeridade para que os Estados prejudicados com a concessão de benefícios ou incentivos fiscais inconstitucionais pudessem questioná-los no STF por meio de reclamação, não sendo necessário trilhar o caminho mais demorado do controle abstrato.

Em 7 de agosto de 2017, após longa discussão no Congresso Nacional, foi editada a Lei Complementar 160/07. A referida lei não substituiu a LC $24 / 75$, que continua em vigor. O escopo principal da nova lei complementar foi conferir aos Estados a possibilidade de regular, mediante convênio, os efeitos das leis estaduais editadas em desconformidade com a LC 24/75 até a data de início de produção dos

${ }^{34}$ CARVALHO, Paulo de Barros. "Guerra Fiscal" e o princípio da não cumulatividade no ICMS. Revista de Direito Tributário, vol. 95. Malheiros, 2006, p. 19.

${ }^{35}$ CARRAZZA, Roque Antonio. ICMS. São Paulo: Malheiros, 2011, p. 393.

36 RMS 33.524/PI, rel. Ministra ELIANA CALMON, rel. p/ acórdão Ministro NAPOLEÃO NUNES MAIA FILHO, Primeira Seção, julgado em 28.08.2013, DJe 07.03.2014.

37 ADI 4481, rel. Ministro Roberto Barroso, Tribunal Pleno, julgado em 11.03.2015, DJe092, divulgado em 18.05.2015, publicado em 19.05.2015. 
efeitos da Lei Complementar. Em outros termos, a LC 160/07 é norma voltada principalmente para regular as situações decorrentes do enorme "passivo" da guerra fiscal, com dezenas de leis estaduais já declaradas inconstitucionais pelo STF.

A Lei Complementar estabeleceu a possibilidade de reconhecer a validade dos atos concessivos de benefícios concedidos em desacordo com a LC 24/75, desde que cumpridas as formalidades indicadas, possibilitando até mesmo a prorrogação de tais benefícios, observados os limites temporais do art. $3^{\circ}$, $\S^{\circ}$, de até quinze anos.

O art. $5^{\circ}$ da LC 160/07 reconheceu que a remissão ou a não constituição de créditos concedidas por lei da unidade federada de origem da mercadoria, do bem ou do serviço afastam as sanções previstas no art. $8^{\circ}$ da Lei Complementar n⿳⺈ 24, de 7 de janeiro de 1975, retroativamente à data original de concessão da isenção, do incentivo ou do benefício fiscal ou financeiro-fiscal. O objetivo da regra é conferir maior segurança ao contribuinte beneficiado pelo incentivo na origem da mercadoria, de forma a impedir a desconsideração, pelo Estado de destino, do benefício, bem como impedir que o Estado de origem se veja na obrigação de exigir os tributos não cobrados, com os acréscimos pertinentes, na hipótese de declaração de inconstitucionalidade de sua lei local.

Note-se ainda que nos termos do art. $8^{\circ}$ da LC 160/07, os convênios com o objetivo de convalidar a concessão de benefícios fiscais passados devem ser aprovados no prazo de cento e oitenta dias da publicação da Lei Complementar, dispositivo que também se justifica pela necessidade de assegurar um mínimo de previsibilidade sobre quais benefícios serão convalidados à luz do novo procedimento.

Em resumo, o que a LC 160/07 possibilitou, em relação aos benefícios editados em desacordo com a LC 24/75, foi a convalidação dos mesmos e a possibilidade de sua manutenção por prazo total de até quinze anos, a depender da atividade objeto do benefício. É interessante notar que tal possibilidade, antes mesmo da edição da LC 160/07, teve reconhecimento da repercussão geral no STF, conforme ementa abaixo:

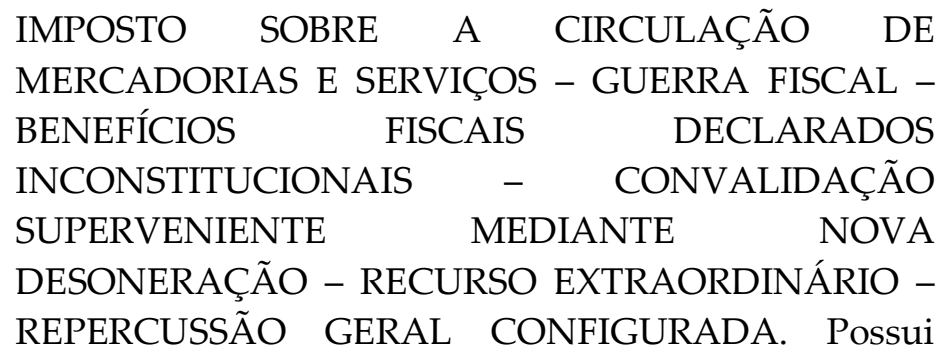


repercussão geral a controvérsia relativa à constitucionalidade da prática mediante a qual os estados e o Distrito Federal, respaldados em consenso alcançado no âmbito do Conselho Nacional de Política Fazendária - CONFAZ, perdoam dívidas tributárias surgidas em decorrência do gozo de benefícios fiscais assentados inconstitucionais pelo Supremo, porque implementados em meio à chamada guerra fiscal do ICMS. (STF, RE 851421 RG/DF, Relator Ministro Marco Aurélio, Tribunal Pleno, julgado em 21.05.2015, publicado em $\left.1^{\circ} \cdot 09.2015\right)$

Apenas em relação aos convênios destinados a regular tal passado de leis estaduais inconstitucionais, o legislador, ciente da impossibilidade de obter tal equacionamento pelo tortuoso caminho da unanimidade, acabou optando pela possibilidade de aprovação dos convênios por dois terços das unidades federadas e um terço das unidades federadas integrantes de cada uma das cinco regiões do Brasil.

Note-se que tal flexibilização da regra da unanimidade da LC 24/75 não se aplica aos convênios futuros, que tenham por objeto a concessão de novos benefícios fiscais que não tenham sido concedidos até data da entrada em vigor da LC 160/17.

Nesse ponto, pode-se realizar uma crítica à postura do legislador que não enfrentou diretamente o problema da unanimidade e do próprio procedimento criado pela LC 24/75. O modelo da deliberação por unanimidade é um dos responsáveis pela notória deterioração do pacto federativo experimentada nos últimos anos, pois acaba por admitir uma postura individualista dos Estados ${ }^{38}$ ao invés de estimular uma relação de cooperação entre os Estados necessária para a manutenção da federação e acaba impondo um modelo autoritário e centralizador muito distante das diretrizes democráticas estabelecidas pela CF. ${ }^{39}$ É especialmente

38 TAVARES, Nathalia de Andrade Medeiros. As proporções do individualismo fiscal dos indivíduos nas guerras fiscais entre os entes da federação: o afastamento da solidariedade social e da justiça distributiva. In: CAMPOS, Carlos Alexandre de Azevedo; IBRAHIM, Fábio Zambitte; OLIVEIRA, Gustavo da Gama Vital. Estudos de federalismo e guerra fiscal, v. 1, Rio de Janeiro: Gramma, 2017, p. 217-251.

${ }^{39}$ ALCOFORADO, Antônio Machado Guedes. Guerra Fiscal: glosas de créditos nas operações incentivadas pelo ICMS e a possibilidade de alteração da LC 24/1975, 
difícil compatibilizar a regra da unanimidade com a necessidade de redução das desigualdades regionais, um dos objetivos expressos da República (art. $3^{\circ}$, III, da CF), ${ }^{40}$ visto que a regra acaba por consolidar, nas mãos dos Estados mais desenvolvidos, o poder de veto em relação a políticas públicas adotadas por Estados menos desenvolvidos. ${ }^{41}$

Ou seja, a LC 160/07 buscou apenas alterar e acrescentar critérios ao modelo já fixado pela Lei Complementar $n^{\circ} 24 / 75$. Contudo, seria mister enfrentar o próprio modelo estabelecido que é oriundo de período histórico no qual o país vivia a centralização do regime militar.com a evidente primazia do governo federal em relação à autonomia estadual. ${ }^{42}$

Embora não tenha flexibilizado a regra da unanimidade para a concessão de benefícios fiscais futuros, a LC 160/07, talvez reconhecendo a ineficácia do modelo do CONFAZ como árbitro das demandas federativas, trouxe importantíssima regra no art. $6^{\circ}$, ao criar sanções mais severas ao Estado que descumpre a LC 24/75. Tais sanções são aplicáveis também para a concessão de benefícios fiscais futuros, ou seja, criados após a edição da LC 160/07.

O art. $6^{\circ}$ da LC 160/07 prevê a aplicação ao Estado faltoso das sanções previstas no art. 23, $\$ 3^{0}$ da Lei Complementar 101/00 (Lei de Responsabilidade Fiscal - LRF), significando que o ente não poderá: 1) receber transferências voluntárias; 2) obter garantia, direta ou indireta, de outro ente e 3) contratar operações de crédito, ressalvas as destinadas ao refinanciamento da dívida mobiliária e as que visem à redução das despesas com pessoal. Tais sanções são aplicadas ao ente político que descumpre os limites de despesas com pessoal fixados na LRF.

A aplicação das sanções é condicionada ao acolhimento, pelo Ministro de Estado da Fazenda, de representação apresentada por Governador de

revogando a previsão de decisão unânime para conceder incentivos fiscais. Revista de Direito Tributário Contemporâneo, Vol. 5, 2017, p. 211-230.

${ }^{40}$ ALMEIDA FILHO, Jorge Celso Fleming. Competição fiscal: uma visão panorâmica. CAMPOS, Carlos Alexandre de Azevedo; IBRAHIM, Fábio Zambitte; OLIVEIRA, Gustavo da Gama Vital. Estudos de federalismo e guerra fiscal, v. 1, Rio de Janeiro: Gramma, 2017, p. 129-174.

41 PENCAK, Nina. Sobre a (in)constitucionalidade dos benefícios fiscais de ICMS concedidos sem convênio. CAMPOS, Carlos Alexandre de Azevedo; IBRAHIM, Fábio Zambitte; OLIVEIRA, Gustavo da Gama Vital. Estudos de federalismo e guerra fiscal, v. 1, Rio de Janeiro: Gramma, 2017, p. 161-218.

42 RIBEIRO, Ricardo Lodi. Paternalismo federativo e a competição para a concessão de benefícios fiscais no ICMS e no ISS. Revista Fórum de Direito Tributário-RFDT, Belo Horizonte, ano 10, n. 59, p. 145, set./out. 2012. 
Estado ou do Distrito Federal. A unidade federada acusada terá o prazo de trinta dias para defesa e a decisão do Ministro da Fazenda será proferida em até noventa dias (art. $6^{\circ}, \S^{\circ} 1^{\circ}$ e $2^{\circ}$ da LC 160/07).

Algumas vantagens do novo procedimento podem ser apontadas. Trata-se de nítida alternativa à "judicialização da guerra fiscal", ou seja, a propositura pelo Estado prejudicado de ADI em face da lei estadual do ente apontado como descumpridor da LC 24/75. Como já destacamos, o julgamento de tais lides no STF não se mostrou eficaz por diversos motivos, como o tempo decorrido até o julgamento, bem como a postura de muitos Estados de editar lei revogando a lei estadual sujeita à ADI para provocar a perda do objeto. Por evidente, o novo procedimento não exclui - e sequer poderia validamente fazê-lo em face da inafastabilidade do controle jurisdicional ${ }^{43}$ - a possibilidade e o Estado, inconformado pela decisão do Ministério da Fazenda, ajuizar ADI para ver examinada sua pretensão.

As sanções indicadas no art. 23, §3ํㅜ da Lei Complementar 101/00 são bastante prejudiciais aos Estados, especialmente considerando a imensa dependência que todos os Estados da federação brasileira possuem das transferências voluntárias e das operações de crédito, como forma de viabilizar parcela significativa dos gastos estaduais. ${ }^{44}$ Prova disso é o esforço que os entes subnacionais realizam para demonstrar, junto ao Governos Federal, o cumprimento dos limites da LRF acerca das despesas com pessoal, de forma a não incidir nas punições da mencionada Lei Complementar. ${ }^{45}$

Logo, a gravidade das novas sanções impostas leva à conclusão de que os Estados terão maior cuidado na concessão de novos benefícios fiscais, de forma a evitar que os Estados prejudicados venham a questionar tais benefícios junto ao Ministério da Fazenda.

É bem verdade que a eficácia de tais sanções pode ser diminuída na hipótese de o Estado faltoso já estiver incidindo nas sanções do art. 23 da LRF pela inobservância das regras sobre controle de limites de gastos com pessoal. No cenário atual de crise fiscal de diversos Estados da federação, tais situações podem ocorrer. Todavia, em uma situação de crise fiscal prolongada, é provável que o Estado venha a aderir ao Regime de

\footnotetext{
43 Art. 5ํㅜ, XXXV, da CF.

${ }^{44}$ Acerca da importância dos recursos federais no cenário atual do federalismo fiscal brasileiro, ALVES, Raquel de Andrade Vieira. Federalismo fiscal brasileiro e as contribuições. Rio de Janeiro: Lumen Juris, 2017.

${ }^{45}$ Há diversas ações judiciais propostas por Governos Estaduais no STF buscando evitar a imposição das sanções previstas na LRF para limites de despesas com pessoal, como, por exemplo, a AC 2659 REF-MC, Tribunal Pleno, Dje 23-09-2010.
} 
COMPETIÇÃO TRIBUTÁRIA OU GUERRA FISCAL? DO PLANO INTERNACIONAL À LEI COMPLEMENTAR Nº 160/2017

Recuperação Fiscal dos Estados, criado pela Lei Complementar 159/2017. $\mathrm{O}$ art. 10 da referida norma estabelece que durante a vigência de tal regime fica suspensa a aplicação do art. 23 da LRF (ressalvado o disposto no inciso I do $\S^{\circ}$ ). Assim, em regra, permanecerá o interesse do Estado de cumprir o procedimento da LC 24/75 para a concessão de benefícios fiscais.

Ademais, o procedimento do art. $6^{\circ}$ da LC 160/07 claramente chamou a responsabilidade da União Federal, por intermédio do Ministério da Fazenda, para a tarefa de assumir o papel de coordenação das demandas federativas e de árbitra das disputas entre governos subnacionais. Como já demonstrado, embora pelo procedimento da LC 24/75, a União Federal já detivesse tal participação, pela presidência do CONFAZ exercida pelo Ministro da Fazenda, a efetividade das deliberações do órgão foi sendo deteriorada em razão do sistemático descumprimento pelos Estados e pela ausência de sanções rápidas e efetivas ao Estado faltoso.

Todavia, ao exercer o papel de árbitro das demandas das unidades federadas na guerra fiscal, é muito importante que o Ministério da Fazenda decida o procedimento do art. $6^{\circ}$ da LC 160/07 com observância da autonomia federativa (art. 18 da CF). Embora a redação do dispositivo possa levar à conclusão de que qualquer benefício fiscal de ICMS concedido pelo Estado "em desacordo com a Lei Complementar no. 24, de 7 de janeiro de 1975" poderia atrair a aplicação das sanções do art. 23 §3ํㅜ da LRF, tal leitura é incompatível com a autonomia federativa e merece receber uma interpretação conforme à Constituição. Isto porque é possível reconhecer hipótese em que a concessão de benefício fiscal de ICMS pelo Estado não é dirigida à atração de investimentos típicos da guerra fiscal. Nesse caso, não há necessidade de que o Estado siga o procedimento da LC 24/75.

Como exemplo de tal situação, podemos invocar o julgamento da ADI 3421/PR (rel. Ministro Marco Aurélio, julgado em 05.05.2010), em que se tratou de benefícios fiscais de ICMS relacionados a serviços públicos voltados para igrejas e tempos religiosos. ${ }^{46}$ No caso, o Governador do Paraná questionou a validade de lei estadual por violação ao artigo 155, $\S 2$ o, inciso XII, "g", da CF. O diploma estadual excluiu a cobrança do ICMS em contas de serviços públicos de fornecimento de água, luz, telefone e gás quando consumidos por igrejas e templos. O Governador

${ }^{46}$ CAMPOS, Carlos Alexandre de Azevedo. ADI 3.421: releitura da "guerra fiscal do ICMS". CAMPOS, Carlos Alexandre de Azevedo; IBRAHIM, Fábio Zambitte; OLIVEIRA, Gustavo da Gama Vital. Estudos de federalismo e guerra fiscal, v. 2, Rio de Janeiro: Gramma, 2017, p. 7-24. 
sustentou a inconstitucionalidade da isenção sem convênio do CONFAZ, nos termos da Lei Complementar no 24/1975.

O ministro Marco Aurélio ressaltou que a hipótese não tratava de mais um caso de "guerra fiscal", cujo objetivo do ente tributante seria de atração de empresas, pois a norma impugnada buscava beneficiar templos de qualquer culto, assim não se poderia concluir por competição federativa para atração de entes religiosos. O Pleno, por unanimidade, seguiu o voto do Relator para julgar improcedente o pedido e assentar a constitucionalidade do ato, sem verificar a violação ao artigo $155, \S 2$, inciso XII, "g", da CF. ${ }^{47}$

Igual raciocínio pode ser aplicado a benefícios ou incentivos fiscais referentes às atividades econômicas que, por razões de fato, não podem ser realizadas em outros locais (v.g., exploração mineral).$^{48} \operatorname{Logo}$, a limitação da competência tributária estadual, fundamentada na regra do art. 155, § 2으, XII, " $\mathrm{g}$ " (que fundamenta a aplicação da LC 24/75) só pode ser admitida nas hipóteses de verdadeiro potencial de disputa entre Estados pela mesma base econômica (guerra fiscal). A limitação é inaplicável nas hipóteses em que tal cenário não pode se verificar mesmo porque inexiste, nesse caso, o potencial conflito de competência tributária que poderia justificar a atuação do legislador complementar, nos termos do art. 146, inciso I, da CF.

\section{CONCLUSÃO}

O Nota-se que, em regra, no plano internacional, para se enfrentar a competição tributária considerada prejudicial ou nociva aos demais países, são utilizados basicamente dois mecanismos legais: por um lado, os tratados e os acordos multilaterais ("hard law"); de outro, as diretrizes da OCDE, consideradas por parte da doutrina como espécie de "soft law". Esta última foi difundida além dos países membros da OCDE, tendo se tornado o melhor instrumento de combate à competição tributária envolvendo a atração do capital financeiro.

${ }^{47}$ CORRÊA, Vanessa Benelli. Guerra fiscal e seus elementos multifatoriais: uma releitura conceitual. CAMPOS, Carlos Alexandre de Azevedo; IBRAHIM, Fábio Zambitte; OLIVEIRA, Gustavo da Gama Vital. Estudos de federalismo e guerra fiscal, v. 1, Rio de Janeiro: Gramma, 2017, p. 251-277.

48 MARINS, Daniel Vieira. OLIVEIRA, Gustavo da Gama Vital de. A autonomia federativa e o problema da unanimidade nos convênios do CONFAZ. Revista do Direito Público, Londrina, v. 12, n. 2, p. 250-272, ago. 2017. DOI: 10.5433/1980511X.2017v12n2p250 
A efetividade dos tratados e acordos multilaterais no enfrentamento da competição tributária entre os países é considerada baixa no plano internacional, tal como ocorre, no plano interno brasileiro, ao se analisar as regras fixadas pela LC 24/75. Enquanto na esfera internacional poucos países buscaram mitigar os problemas da competição tributária por meio de acordos multilaterais ou tratados, no Brasil, as normas que regulam as concessões de benefícios e incentivos fiscais, contidas na lei complementar, são frequentemente desrespeitadas, gerando o fenômeno da "inconstitucionalidade útil". Por conseguinte, se verifica que a eficácia do "hard law" no plano internacional é tão limitada quanto a sua congênere no âmbito interno nacional, o que indica a insuficiência do instituto do "hard law" e das regras impositivas do ordenamento legal brasileiro.

Por conseguinte, no Brasil, uma alternativa à fixação de regras legais estanques com o objetivo de impedir a competição tributária prejudicial seria a criação de normas visando à cooperação entre os Estadosmembros da Federação, tendo o Ministro de Estado da Fazenda a função de árbitro antes os conflitos fiscais existentes. Tal como feito no plano internacional - em que a competição tributária foi enfrentada por meio de normas ou diretrizes que, apesar de não serem reconhecidas como direito propriamente dito, geram efeitos que suscitam um processo legal -, podem ser criados mecanismos próximos do "soft law" para se tratar da questão na realidade interna brasileira, de modo que se alcance uma maior eficácia quanto à regulação da competição tributária por meio das normas fixadas em lei complementar.

Nesse aspecto, a LC 160/07 deu início a um novo caminho a ser trilhado pela legislação complementar, afastando-se da mera proibição da competição tributária em favor da tomada de decisão pela maioria (e não pela unanimidade) dos Estados em casos envolvendo incentivos e benefícios fiscais do passado e da atuação relevante do Ministro de Estado da Fazenda como espécie de árbitro da Federação. Paralelamente, criou-se um mecanismo de maior eficácia quanto às sanções a serem impostas aos Estados que violem a legislação complementar, qual seja, a aplicação do art. 23, §3ํㅡ, da Lei de Responsabilidade Fiscal (Lei Complementar $\left.n^{\circ} 101 / 00\right)$, o que permitirá que um número menor de ações diretas de inconstitucionalidade sejam ajuizadas pelos Estados, bem como se afaste o fenômeno da "inconstitucionalidade útil" oriundo dos efeitos limitados das decisões proferidas pelo Supremo Tribunal Federal. 


\section{REFERÊNCIAS}

ALCOFORADO, Antônio Machado Guedes. Guerra Fiscal: glosas de créditos nas operações incentivadas pelo ICMS e a possibilidade de alteração da LC 24/1975, revogando a previsão de decisão unânime para conceder incentivos fiscais. Revista de Direito Tributário Contemporâneo, v. 5, 2017.

ALMEIDA FILHO, Jorge Celso Fleming. Competição fiscal: uma visão panorâmica. CAMPOS, Carlos Alexandre de Azevedo; IBRAHIM, Fábio Zambitte; OLIVEIRA, Gustavo da Gama Vital. Estudos de federalismo e guerra fiscal, v. 1, Rio de Janeiro: Gramma, 2017.

ALVES, Raquel de Andrade Vieira. Federalismo fiscal brasileiro e as contribuições. Rio de Janeiro: Lumen Juris, 2017.

BOADWAY, Robin. Canada. The practice of fiscal federalism: comparative perspectives.Org. Anwar Shah. Montreal \& Kingston: McGill-Queen's University Press, 2007.

BRASIL. Governo federal. Lei $\mathbf{n}^{\circ}$ 9.430/96. Disponível em: $<$ http://www.planalto.gov.br/ccivil 03/LEIS/L9430.htm>. Acesso em 30 set. 2017.

. Receita Federal do Brasil. IN SRF 407/2004. Disponível em: $<$ http://normas.receita.fazenda.gov.br/sijut2consulta/link.action?visao=a notado\&idAto=15307>. Acesso em 30 set.2017.

. Receita Federal do Brasil. IN RFB 1037/2010. Disponível em: $<\underline{\text { http://normas.receita.fazenda.gov.br/sijut2consulta/link.action?visao=a }}$ notado\&idAto=16002>. Acesso em 30 set. 2017.

BRASIL. Superior Tribunal de Justiça. Recurso em Mandado de Segurançan $^{\circ}$ 33.524/PI, rel. Ministra Eliana Calmon, rel. p/ acórdão Ministro Napoleão Nunes Maia Filho, Primeira Seção, julgado em 28.08.2013, Lex: jurisprudência do STJ, DJe 07.03.2014.

. Supremo Tribunal Federal. Ação Direta de Inconstitucionalidade $\mathrm{n}^{\circ}$ 44 81 , rel. Ministro Roberto Barroso, Tribunal Pleno, julgado em 11.03.2015, Lex: jurisprudência do STF, DJe-092, divulgado em 18.05.2015, publicado em 19.05.2015. 
Supremo Tribunal Federal. Recurso Extraordinário n 851421 $\overline{\mathrm{RG}} / \mathrm{DF}$, rel. Ministro Marco Aurélio, Tribunal Pleno, julgado em 21.05.2015, Lex: jurisprudência do STF, DJe-171, divulgado em 31.08.2015, publicado em $1^{\circ} .09 .2015$.

CAMPOS, Carlos Alexandre de Azevedo. ADI 3.421: releitura da "guerra fiscal do ICMS". CAMPOS, Carlos Alexandre de Azevedo; IBRAHIM, Fábio Zambitte; OLIVEIRA, Gustavo da Gama Vital. Estudos de federalismo e guerra fiscal, v. 2, Rio de Janeiro: Gramma, 2017.

CARRAZZA, Roque Antonio. ICMS. São Paulo: Malheiros, 2011.

CARVALHO, Paulo de Barros. "Guerra Fiscal" e o princípio da não cumulatividade no ICMS. Revista de DireitoTributário, vol. 95. Malheiros, 2006.

CHRISTIANS, Allison. Hard Law \& Soft Law in International Taxation. Wisconsin International Law Journal, Vol. 25, No. 2, Madison: University of Wisconsin Law School, 2007. Disponívelem: $<$ https://ssrn.com/abstract=988782>. Acessoem: 21 out.2017.

Sovereignty, Taxation, and Social Contract. Minnesota Journal of International Law, Vol. 18, Madison: University of Wisconsin Law School, 2008. Disponível em: $<$ https://ssrn.com/abstract $=1259975>$. Acesso em: 29 set.2017.

CORRÊA, Vanessa Benelli. Guerra fiscal e seus elementos multifatoriais: uma releitura conceitual. CAMPOS, Carlos Alexandre de Azevedo; IBRAHIM, Fábio Zambitte; OLIVEIRA, Gustavo da Gama Vital. Estudos de federalismo e guerra fiscal, v. 1, Rio de Janeiro: Gramma, 2017.

DERYUGIN, Alexander; KURLYANDSKAYA, Galina. The Russian Federation. The practice of fiscal federalism: comparative perspectives. Org. Anwar Shah. Montreal \& Kingston: McGill-Queen's University Press, 2007.

FOX, William F. The United States of America. The practice of fiscal federalism: comparative perspectives. Org. Anwar Shah. Montreal \& Kingston: McGill-Queen's University Press, 2007. 
KIRCHGÄSSNER, Gebhard. Swiss Confederation. The practice of fiscal federalism: comparative perspectives. Org. Anwar Shah. Montreal \& Kingston: McGill-Queen's University Press, 2007.

LAMPREAVE, Patricia. Fiscal Competitiveness versus Harmful Tax Competition in the European Union. Bulletin for InternationalTaxation, v. 65, 2011. Disponível em: $<$ http://ssrn.com/abstract=1932257 $>$. Acesso em 30 set.2017.

MARINS, Daniel Vieira; OLIVEIRA, Gustavo da Gama Vital de. A autonomia federativa e o problema da unanimidade nos convênios do CONFAZ. Revista do Direito Público, Londrina, v. 12, n. 2, ago. 2017. DOI: 10.5433/1980-511X.2017v12n2p250.

MORRISS, Andrew P.; MOBERG, Lotta, Cartelizing Taxes: Understanding the OECD's Campaign Against 'Harmful Tax Competition'. Columbia Journal of Tax Law, Vol. 4, No. 1, 2013, New York: Columbia University, 2013, p. 5 e 14. Disponível em: $<$ https://ssrn.com/abstract=1950627>. Acesso em: 30 set.2017.

ORGANIZAÇÃO MUNDIAL DO COMÉRCIO (OMC). “The WTO... ... In brief". 2017.2 Disponível $<$ https://www.wto.org/english/thewto e/whatis e/inbrief e/inbr00 e.ht $\underline{\mathrm{m}}>$. Acesso em 29 set. 2017.

ORGANIZAÇÃO PARA A COOPERAÇÃO E DESENVOLVIMENTO ECONÔMICO (OCDE). List of OECD Member countries - Ratification of the Convention on the OECD. 2017 (2017). Disponível em: $<$ http://www.oecd.org/about/membersand partners/list-oecd-membercountries.htm>. Acesso em: 22 out. 2017.

.Organisation for Economic Co-operation and Development, Harmful Tax Competition: An Emerging Global Issue, 1998. Disponívelem: <http://www.uniset.ca/microstates/oecd 44430243.pdf >. Acessoem: 21 out. 2017.

Peer pressure: a related concept. 2017 (2017a) Disponível em: $<\underline{\text { https://www.oecd.org/site/peerreview/peerpressurearelatedconcept.ht }}$ m>. Acesso em: 29 set. 2017. 
PENCAK, Nina. Sobre a (in)constitucionalidade dos benefícios fiscais de ICMS concedidos sem convênio. CAMPOS, Carlos Alexandre de Azevedo; IBRAHIM, Fábio Zambitte; OLIVEIRA, Gustavo da Gama Vital. Estudos de federalismo e guerra fiscal, v. 1, Rio de Janeiro: Gramma, 2017.

RIBEIRO, Ricardo Lodi. Paternalismo federativo e a competição para a concessão de benefícios fiscais no ICMS e no ISS. Revista Fórum de Direito Tributário - RFDT, Belo Horizonte, ano 10, n. 59, set./out. 2012.

RIXEN, Thomas. Tax Competition and Inequality - The Case for Global Tax Governance. Global Governance: A Review of Multilateralism and International Institutions, Vol. 17, 2011. Disponível em: $<$ https://ssrn.com/abstract=1488066 > . Acesso em: 12 out. 2017.

TAVARES, Nathalia de Andrade Medeiros. As proporções do individualismo fiscal dos indivíduos nas guerras fiscais entre os entes da federação: o afastamento da solidariedade social e da justiça distributiva. In: CAMPOS, Carlos Alexandre de Azevedo; IBRAHIM, Fábio Zambitte; OLIVEIRA, Gustavo da Gama Vital. Estudos de federalismo e guerra fiscal, v. 1, Rio de Janeiro: Gramma, 2017.

VARGA, Caio Amuri. Guerra fiscal - ausência de coordenação na política pública tributária nacional. Revista Tributária e de Finanças Públicas, v. 122, 2015.

COMPETIÇÃO TRIBUTÁRIA OU GUERRA FISCAL? DO PLANO INTERNACIONAL À LEI COMPLEMENTAR N ${ }^{\circ}$ 160/2017

TAX COMPETITION OR FISCAL WAR? FROM THE INTERNATIONAL PLAN TO COMPLEMENTARY LAW $\mathrm{N}^{\circ} 160 / 2017$ 